\title{
Effects of Application of Independant Research-Based Assignments on Students' Results
}

\begin{abstract}
Zenel Sina
Centre for Continuous Education

Faculty of Education

University "A. Moisiu" Durrës, Albania

Doi:10.5901/jesr.2013.v3n3p419

Tel. 0894060094 E-mail: zenelsina@hotmail.com

Abstract

This article is based on the applications of inqury-based learning techniques in a private grade school. Effects of inqury-based learning (aka IBL) have been observed and quantified during this experiement. Ammeloriation of the learning environment, adoptation of diverse learning techniques as well as increase of student responsibilities in the learning process, all result in an overall increased student motivation, as well as increased grades in tests. Parents feel the difference in their children's attitute and behaviour, and are inclined to get actively involved in IBL activities.From the meta-analysis of the systematic data, it was concluded that the most effective elements in motivating students and increasing learning outcomes, were level of taking responsibility, the atmosphere of presenting the homework, and the individual skills in active and authentic learning. Application of IBL in this research shows a change in managment of student behaviour, by reducing the number of rules and alternating some of the rules as per students suggestions. Also, it is observed a reduced level of disciplinary measures compared to the average disciplinary actions per class, and the disciplinary actions taken before this experiment.
\end{abstract}

Key words: IBL, learning environment, independant research work, student results, authentic learning, selfregulation of learning, learning responsibility.

\section{Introduction}

This article explores the result of the application of inqury-based learning strategies in the private middle school "Univers", located in Tirana. Observations have been recorded during a one school-year period, starting from Fall 2011 until Summer 2012.

"Univers" middle school started operating in 1999 based on the verdict of Tribunal of Tirana, and the approval of the Ministry of Education and Science. The institution follows the legislations set in place for operation of private schools, and it is characterized by a high level of democracy in its operations. The educational staff (teachers), the student representatives and parents are integral part of the decision-making process in this institution. Teaching process is based on a student-centered application of teaching. Among other strategies that arise from this philosophy, this institution employes inqury-based learning strategies. This strategies rise on the background of the theories of Dewey, Montessorit, Piaget, Vigotsky, Bruner, Costa,etc.

During this study, it has been systematically observed the effect of independant of research work on students' grades. Teachers were trained based on the Inquary-Based Learning modules, to effectively assess students' work and achievements.

\section{Inqury, hypothesis and variables}

The main question this study focuses on are :

a) Will the application of inqury-based learning strategies affect the achievements of the students?

b) Will student engagement and interactive learning increase, if students face more research-based assignments?

c) Will parents be more involved in their child's learning process, if the child is assigned more independant research-based homeworks? 
d) Will the application of inqury-based learning strategies affect students' behaviour and attitude towards school's regulations?

Hypothesis: Teaching and inqury based learning affect and increase students' results (achievements) at the end of the process.

Dependand Variable: Students' results (achievements) which are based on the opinions of the teacher.

Independant variable: The independant research-based assignments, expressed in students' standing and the format of program planning created by the teachers.

\section{Terms and main concepts}

a) Inqury-based learning

Inqury-based learning (IBL) is a pedagogical strategy based on the premise of learning based on research of information sources, experimental trials, discussion of results and presentation of the ideas in front of the peers, who help shaping this ideas. (Won, M. 2009) Teachers use the analogy of the bee to describe this strategy. Same as bees go after nectar in flowers and use it to make honey in their hives, same way the students search for information from different sources, and use the classroom as their hive to produce their research-based assignments. According to this practice, all the activities in class focus on the use of the information, being observant, developing critical thinking.

During this process, the student is actively the focus of the process, and the teacher, technological resource, scholarly materials etc. are all a tool supporting learning. The teacher, similarly to the student, assumes the role of an advanced learner that becomes part of the process. (Keller,J.M 2010) The evaluation in this process is not mearly a grade, but the active engagement of the student, and the thrive of open mindsets.

The lesson begins with questions and the student is looking for answers through level assignments and the increase of the level of difficulty gradually (Rooney.C. 2009).

The student tries to work individually based on own experience and previous knowledge. Then, the assignment is broken out in teams of two or groups, where everyone assumes roles and responsibilities. When the assignment was chosen by the student themself, they can create groups and ask for assistance and guiding in breaking out the assignment. If the project is big and it requires involvment of many people, then the student assumes a role, which he has to comply to based on the rules and agreements set beforehand. (Sina.Z. 2011)

The homework is used as a preparing step or reflection of the learning. Assignments are a unique part of the learning process. They set the conditions for the smooth progress of the learning process. The student presents, discusses and reflects on his/her own ideas. This idea does not necessarily need to be correct. If this idea is incorrect, the student will in no way be penalized, discreted or bullied for his product. Everyone should learn in the process, even from the mistakes. (Ebanks , A. R. 2010)

The learning environment is very important in the constructive learning process, which is why the process is managed through a positive discipline. Teacher's proactivity in motivation, pointing to guidilines and social expression of ideas accepted by all the "members of the organization", are qualities that are actively expressed during learning process through this strategies. (ON,H.CH. 2010)

When assigning the homework, the teacher evaluates the intelligence, the style of learning, the environment and the motivation in each student. (Cooper. 2007)

\section{b) Results in learning}

Results comprise marks in tests, the assignments completed, active engagement of students in the learning process, involvement in projects, the will and determination to present the work, involvement of parents in the homework of their children, as well as the quality of the completed assignments.

\section{c) Learning environment}

Learning environment is related to the optimal conditions that favour learning, without struggle or stress. Ammeloration of 
the learning environment includes also the teaching techniques and students' responsibilities in their learning process.

The assignment has to be clear before being assigned, so that it can avoid confussion and frustration along the way. This clarification should be an ongoing process where both the student and the parents are involved.

The teacher plans out the teaching strategies and designs their dynamic implementation. This strategies focus on interactivity of classroom as a whole entity, the possibility for continuous education and ensuring unlimited learning environment.

The teacher collaborates with multidisciplinary teams to diagnose problems in learning process, assigns and assumes responsibilities. Student also assume responsibility as a factor in the learning process.

Another factor that influences the learning environment is finding or making partners in education.

The creation of rules and guidelines, that have a wide base and their institutionalization creates the dimensions of the learning environment and makes all parties assume responsibilities in the learning process.

\section{Methods}

The teachers of the school were trained based on IBL modules. The training program comprised 6 credits (36 hours of theory and 150 hours of practice). Teachers followed the platforms built by intradisciplinary teams, to build their own teaching program and plan.

During the teaching process, teachers followed step by step the process and analysed their progress every weekend, when they picked effective techniques and practices of research. The process was actively monitored from teachers through notes in the database (check-list).

The research method adopted was ex post facto (Cohen,L. and Manion, L. \& Morrison, K. 2000) In the database were recorded marks in the pre-tests, marks in the final tests, amount of research-based assignments assigned compared to the total number of assignments, the authority assigning or undertaking the assignment, and some comments (qualitative descriptions) of the students' behaviour, attitudes and parents' involvement.

Focus groups were created and students, teachers, and parents were interviewed. The homeworks, portfolios of students and teachers, presentations and products of the research-based work were assesed to determine the students' performances.

Meta-analysis was used to discuss the statistical observation during this study.

\section{Process of data accumulation}

When it comes to results, marks are the most important element of assesment (in the Albanian context). In the final database the marks in the pretest were compared to those in the final test. Marks were compared for each student individually, and averages of the class for each test. In both tests the maximal amount of points was the same. Not only were marks compared, but the amount of points obtained in each test was also looked into.

Students express their level of motivation regardless of their type, level or the attitude of their parents and teachers. The difference between the assigned homework and the completed homeworks was an assesment element of expected progress.

\section{Results:}

One of the first questions this study raised was whether the application of independant research-based assignments will affect the achievements of the students. Comparing the marks from the pretest (administered before the experiment) and the final test (administered at the end of the chapters, for different subjects) show some differences.

In the subject "Albanian Language 3" the approach had little effect. The difference of the averages between the two tests is 0.22 . The difference consists in the distribution of marks with less students getting extreme marks " 4 "," 5 " and "10", and more receiving a mark between "7"-" 8 ". In fifth grade, the results are more satisfying for the subject "Knowledge of nature 5", where the difference was +2.13. In "Albanian Language 5" the difference between the averages of both tests is 0.75 , whereas "Mathematics 5 " shows an average of +1.10 .

From the analysis of all the results, it is observed that increasing research-based assignments has a lower influence in subjects such as languages and mathematics, but does prove effective on "Knowledge of nature". 
Application of independant research-based homeworks showed an increased interest and involvement from parents. Their engagements was expressed through the support they should towards their children in helping them obtain the information, display and present it, and set up posters and PowerPoint presentations.

During the application process of the independant research-based assignments, students show engagement and will to present their work in front of an audience. According to evidence, the research based assignments were all completed from all students. During the assigning of the traditional homeworks, only some of the students completed their homeworks systematically.

Research-based assignments were in $60 \%$ of the cases picked by students themselves and were discussed in class. The traditional homeworks are assigned by the teacher and are only marked after four to five more assignments.

\section{Recommendations}

For the successful application of inqury-based learning strategies, it is important that the teachers are properly trained based in IBL learning modules.

To advance long term inqury-based learning, as well as to enhance critical thinking, teachers should intensively assign independant research-based assignments.

When assigning independant research-based assignments, teachers should pay attention to engaging students in a pre-planned delivery project.

When assigning homework, teachers should consider the involvement of parents.

To increase interest and motivation, teachers should invite parents during the presentation of the students' independant research-based assignments, since parents are an active part of the process.

\section{References}

Bessick, C. Sh. (2008): Improved critical thinking skills as a result of direct instruction and their relationship to academic achievement

Brune, C. M. (2010):The inquiry learning model as an approach to mathematics instruction:

CHAN, HOK,ON (2010) How do teachers' beliefs affect the implementation of inquiry-based learning in the PGS Curriculum? A case study of two primary schools in Hong Kong., Durham theses, Durham University. Available at Durham E-Theses Online: http://etheses.dur.ac.uk/320/

Ebanks, A. R. (2010) "The Influence of Learner-centered Pedagogy on the Achievement of Students in Title I Elementary Schools"

Keller, J. M. (1983). Motivational design of instruction. In C. M. Reigeluth (Ed.), Instructional-design theories and models: An overview of their current status. Hillsdale, $\mathrm{NJ}$ :

Keller,J.M (2010) "Motivational design for learning and performance/ The ARCS model aproach"

Lawrence Erlbaum Associates. . www.learning-theories.com/kellers-arcs-model-of-motivational-design.ht

Orrill, H.Ch(2002):Learning Objects to Support Inquiry-Based, Online Learning

Rooney.C. (2009): "How am I using inquiry-based learning to improve my practice and to encourage higher order thinking among my students of mathematics?

Roy A. Ebanks , A. R. (2010) "The Influence of Learner-centered Pedagogy on the Achievement of Students in Title I Elementary Schools"

Won.M (2009): "Issues in inquiry-based science education seen through dewey's theory of inquiry" 